\title{
Enhanced performance of cobalt ferrite encapsulated in graphitic shell by means of AC magnetically activated catalytic wet peroxide oxidation of 4- nitrophenol
}

\author{
Rui S. Ribeiro ${ }^{\mathrm{a}, \mathrm{b}}$, Juan Gallo ${ }^{\mathrm{c}}$, Manuel Bañobre-López ${ }^{\mathrm{c}}$, Adrián M.T. Silva ${ }^{\mathrm{b}}$, Joaquim L. Faria ${ }^{\mathrm{b}}$, \\ Helder T. Gomes ${ }^{\mathrm{a}, \mathrm{b}, *}$ \\ a Centro de Investigação de Montanha (CIMO), Instituto Politécnico de Bragança, 5300-253 Bragança, Portugal \\ ${ }^{\mathrm{b}}$ Laboratory of Separation and Reaction Engineering - Laboratory of Catalysis and Materials (LSRE-LCM), Faculdade de Engenharia, Universidade do Porto, Rua Dr. \\ Roberto Frias, 4200-465 Porto, Portugal \\ ${ }^{c}$ Advanced (Magnetic) Theranostic Nanostructures Lab, Department of Life Sciences, INL - International Iberian Nanotechnology Laboratory, Av. Mestre José Veiga, 4715- \\ 330 Braga, Portugal
}

\section{H I G H L I G H T S}

- CWPO experiments were performed in the presence of an AC magnetic field.

- The tandem effect of a magnetic field on CWPO is described.

- The new process was coined as magnetically activated CWPO (MACWPO).

- One ferromagnetic graphitic nanocomposite was employed in the MACWPO process.

- MA-CWPO markedly increase both 4NP removal and organic mineralization.

\section{A R T I C L E I N F O}

\section{Keywords:}

CWPO

Magnetic hyperthermia

Core-shell nanocomposites

Ferromagnetic composites

Heterogeneous Fenton process
G R A P H I C A L A B S T R A C T

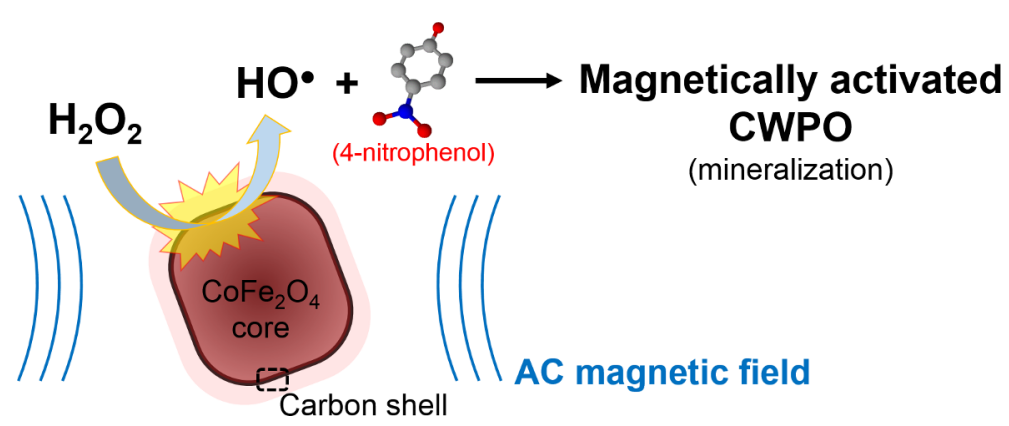

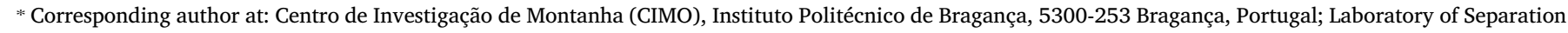

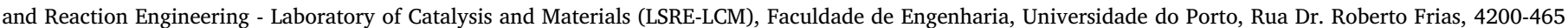
Porto, Portugal.

E-mail address: htgomes@ipb.pt (H.T. Gomes). 
nanoparticulated catalyst to an AC magnetic field, which accelerates the catalytic decomposition of $\mathrm{H}_{2} \mathrm{O}_{2}$ via hydroxyl radicals $\left(\mathrm{HO}^{\circ}\right)$ formation.

\section{Introduction}

In recent years, magnetic materials have been extensively applied in catalytic wet peroxide oxidation (CWPO), either directly as catalysts or included in different support/hybrid materials (e.g., alumina, silica, carbon materials, zeolites, pillared clays and minerals) [1-9]. The catalytic activity of these materials is mainly a consequence of the wellknown ability of some metal species to promote the decomposition of hydrogen peroxide $\left(\mathrm{H}_{2} \mathrm{O}_{2}\right)$ via hydroxyl radicals ( $\left.\mathrm{HO}^{\circ}\right)$ formation. This reaction can be generally described by Eq. (1) [2,8], in which $\mathrm{M}$ represents a metal with at least two possible oxidation states (e.g., $\mathrm{M}^{\mathrm{n}+}$ and $\mathrm{M}^{(\mathrm{n}+1)+}$ ). Once formed, $\mathrm{HO}^{\circ}$ radicals are the effective species for the degradation of most of the organic pollutants present in waste waters $[9,10]$.

$\mathrm{H}_{2} \mathrm{O}_{2}+\mathrm{M}^{\mathrm{n}+} \rightleftarrows \mathrm{HO}^{\bullet}+\mathrm{M}^{(\mathrm{n}+1)+}+\mathrm{OH}^{-}$

Despite all the research conducted on the application of magnetic materials in CWPO, the magnetic properties of these materials, such as their ability to locally convert magnetic induction into heat, remain unexplored [1-9]. At most, magnetic separation systems have been employed for catalyst recovery after the treatment stage. This is the case of our previous work, in which the high catalytic activity and stability of a magnetic graphitic nanocomposite (MGNC) - composed by a cobalt ferrite core and a graphitic shell $\left(\mathrm{CoFe}_{2} \mathrm{O}_{4} / \mathrm{MGNC}\right.$ ), was maintained through a series of five CWPO reaction/magnetic separation sequential experiments in the same vessel, with consecutive catalyst reuse [11].

On the other hand, iron-based magnetic nanomaterials, such as magnetite and cobalt ferrite, have received a great deal of attention from the biomedical research community, especially in the field of magnetic hyperthermia for cancer treatment [12-15]. This innovative treatment technique relies on the ability of magnetic nanoparticles to release heat upon exposure to an alternating current (AC) magnetic field, as a result of several heat dissipation mechanisms, including hysteresis losses, and Brownian and Néel relaxation [14-17] - a concept that can be extended to water treatment.

Seeking to further explore the potential arising from the application of magnetic materials in CWPO, by taking advantage of the heat dissipation properties of cobalt ferrite nanomaterials when exposed to an AC magnetic field, preliminary experiments were performed with the ferromagnetic $\mathrm{CoFe}_{2} \mathrm{O}_{4} / \mathrm{MGNC}$ catalyst developed in our previous work [11]. The coupling of the AC magnetic field to the CWPO process was here denoted as magnetically activated catalytic wet peroxide oxidation (MA-CWPO). Following the experimental methodology of our recent works, 4-nitrophenol (4-NP) was used as aqueous model system $\left(5.0 \mathrm{~g} \mathrm{~L}^{-1}\right)$ of refractory organic pollutants typically not removed by conventional biological treatment technologies $[11,18]$.

\section{Materials and methods}

\subsection{Chemicals}

4-Nitrophenol (98 wt\%) and hydrogen peroxide (30\% w/v) were purchased from Acros Organics and Fluka, respectively. Iron (III) chloride hexahydrate ( $97 \mathrm{wt} \%)$, phenol $(99.5 \mathrm{wt} \%)$ and formaldehyde solution (37 wt\%, stabilized with methanol) were obtained from Panreac. Titanium (IV) oxysulphate (15 wt $\%$ in diluted sulphuric acid, $99.99 \%$ ), iron (II) chloride tetrahydrate (99 wt\%), copolymer pluronic F127 and sodium sulphite $(98 \mathrm{wt} \%)$ were purchased from SigmaAldrich. Sodium hydroxide (98.7 wt\%), sulphuric acid ( $95 \mathrm{wt} \%$ ), methanol (HPLC grade), glacial acetic acid (analytical reagent grade), tertbutanol (99.8 wt\%) and acetonitrile (HPLC grade) were obtained from Fisher Chemical. Distilled water was used throughout the work.

\subsection{Catalyst preparation}

$\mathrm{CoFe}_{2} \mathrm{O}_{4}$ nanoparticles were prepared by co-precipitation of $\mathrm{Co}^{2+}$ and $\mathrm{Fe}^{3+}$ in basic solution at $348.2 \mathrm{~K}$, followed by thermal treatment under a purified air flow at $773.2 \mathrm{~K}$. $\mathrm{CoFe}_{2} \mathrm{O}_{4} / \mathrm{MGNC}$ was prepared by hierarchical co-assembly of $\mathrm{CoFe}_{2} \mathrm{O}_{4}$ nanoparticles and carbon precursors, followed by thermal annealing, as depicted in Fig. 1. A thorough description of the synthesis procedure can be found in our previous publication [11].

\subsection{Magnetic properties characterization}

The magnetic properties of $\mathrm{CoFe}_{2} \mathrm{O}_{4} / \mathrm{MGNC}$ were characterized with a superconducting quantum interference vibrating sample magnetometer (SQUID-VSM) from Quantum Design, adapting the procedure described elsewhere [19]. For that purpose, the hysteresis curves were obtained for magnetic fields in the range -20 to $20 \mathrm{kOe}$, at $300 \mathrm{~K}$. The temperature-dependent magnetization was obtained under zerofield-cooling and field-cooling (ZFC-FC) conditions for temperatures in the range $2-300 \mathrm{~K}$, with an applied magnetic field of $100 \mathrm{Oe}$. The magnetic properties of the catalyst recovered after a MA-CWPO run were also characterized. In this case, the catalyst was recovered after the reaction stage, washed and dried overnight in an oven at $60^{\circ} \mathrm{C}$. Afterwards, its magnetic properties were characterized according to the above described experimental procedures.

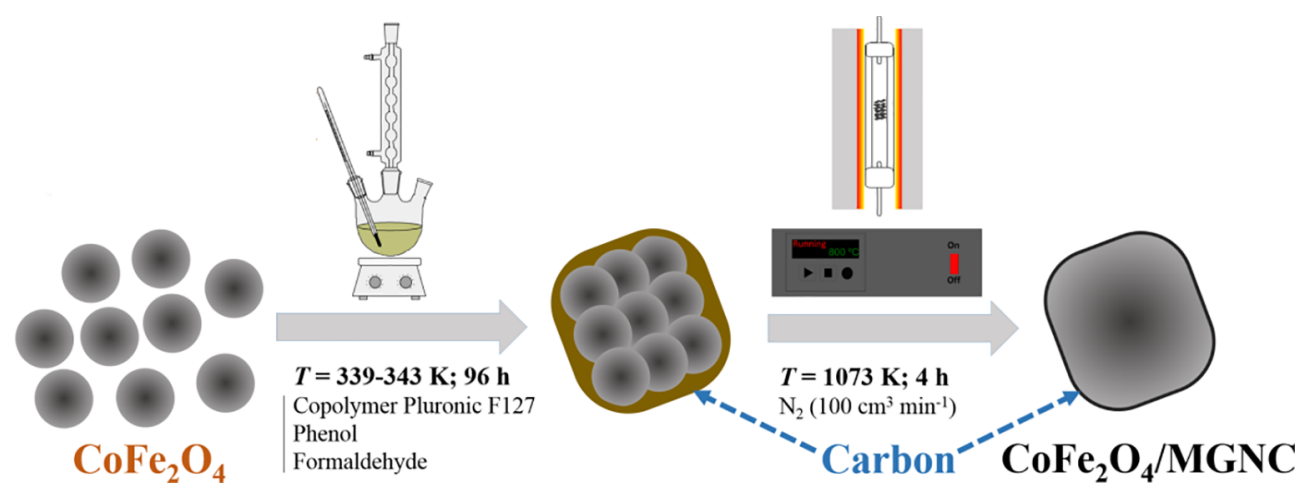

Fig. 1. Synthesis of $\mathrm{CoFe}_{2} \mathrm{O}_{4} / \mathrm{MGNC}$ by hierarchical co-assembly of $\mathrm{CoFe}_{2} \mathrm{O}_{4}$ nanoparticles and carbon precursors, followed by thermal treatment. 


\subsection{Magnetically activated experiments}

Batch CWPO experiments in the presence and absence of an AC magnetic field were performed at room temperature $(297.2 \pm 0.4 \mathrm{~K})$, in a $100 \mathrm{~mL}$ glass beaker with mechanical stirring $(700 \mathrm{rpm})$. The beaker was loaded with 4-NP aqueous solutions $\left(5.0 \mathrm{gL}^{-1}\right.$, i.e. $0.036 \mathrm{M})$. In magnetically activated catalytic wet peroxide oxidation (MA-CWPO) runs, the beaker was placed inside of an electromagnetic coil to allow the application of an AC magnetic field (cf. Fig. 2). The $\mathrm{pH}$ of the 4-NP solutions was previously adjusted to 3 by means of $\mathrm{H}_{2} \mathrm{SO}_{4}$ and $\mathrm{NaOH}$ solutions. The experiments were allowed to proceed freely, without further $\mathrm{pH}$ conditioning. $\mathrm{H}_{2} \mathrm{O}_{2}(30 \% \mathrm{w} / \mathrm{v})$ was then injected into the system, in order to reach the non-catalytic stoichiometric amount of $\mathrm{H}_{2} \mathrm{O}_{2}$ needed to completely mineralise 4-NP $\left(17.8 \mathrm{~g} \mathrm{~L}^{-1}\right.$; i.e., considering the direct reaction of 4-NP with $\mathrm{H}_{2} \mathrm{O}_{2}$, leading to the formation of carbon dioxide, water and nitrate). The catalyst was added after complete homogenization of the resulting solution, that moment being considered as $t_{0}=0 \mathrm{~min}$. The AC magnetic field was applied with a frequency of $533.9 \mathrm{kHz}$ and a nominal coil field at maximum of $240 \mathrm{G}$. A Magnetherm ${ }^{\mathrm{TM}}$ apparatus (NanoTherics Ltd) equipped with a watercooling system was used in order to control the electromagnetic coil temperature. The experimental set-up is shown in Fig. 2.

A pure adsorption run was performed in order to assess the possible influence of adsorption on the 4-NP removal by CWPO, but, in this case, the amount of $\mathrm{H}_{2} \mathrm{O}_{2}$ was replaced by distilled water. A blank experiment, without any catalyst, was carried out to assess possible non-catalytic oxidation promoted by $\mathrm{H}_{2} \mathrm{O}_{2}$. A MA-CWPO run was performed in the presence of tert-butanol $(t-\mathrm{BuOH} ; 0.809 \mathrm{M})$, which is a known scavenger of $\mathrm{HO}^{\circ}$ radicals [20] that allows to indirectly predict the participation of these radicals in the process. All these three experiments were performed under the same AC magnetic field conditions. Room and solution temperatures were monitored during the experiments. All the experiments were performed considering the mass ratio $[4-\mathrm{NP}]_{0} /$ $\left[\mathrm{CoFe}_{2} \mathrm{O}_{4}\right]=6.9$, corresponding to a mass ratio $[4-\mathrm{NP}]_{0} /\left[\mathrm{CoFe}_{2} \mathrm{O}_{4} /\right.$ MGNC $]=1\left(14.4 \mathrm{wt} \%\right.$ of $\mathrm{CoFe}_{2} \mathrm{O}_{4}$ in $\mathrm{CoFe}_{2} \mathrm{O}_{4} / \mathrm{MGNC}$, as determined by thermogravimetric analysis in our previous publication [11]). A homogeneous CWPO run was performed using iron (II) chloride tetrahydrate and cobalt (II) chloride hexahydrate as source of $\mathrm{Fe}^{2+}$ and $\mathrm{Co}^{2+}$, respectively.

\subsection{Analytical methods}

The amounts of 4-NP and oxidation by-products were determined by high performance liquid chromatography (HPLC). The amount of $\mathrm{H}_{2} \mathrm{O}_{2}$ was determined by a colorimetric method. Additional details on these analytical methods can be found elsewhere [18]. Total organic carbon (TOC) was determined using a Shimadzu TOC-L CSN analyser. Dissolved iron and cobalt contents were determined by inductively coupled plasma optical emission spectrometry (ICP-OES).
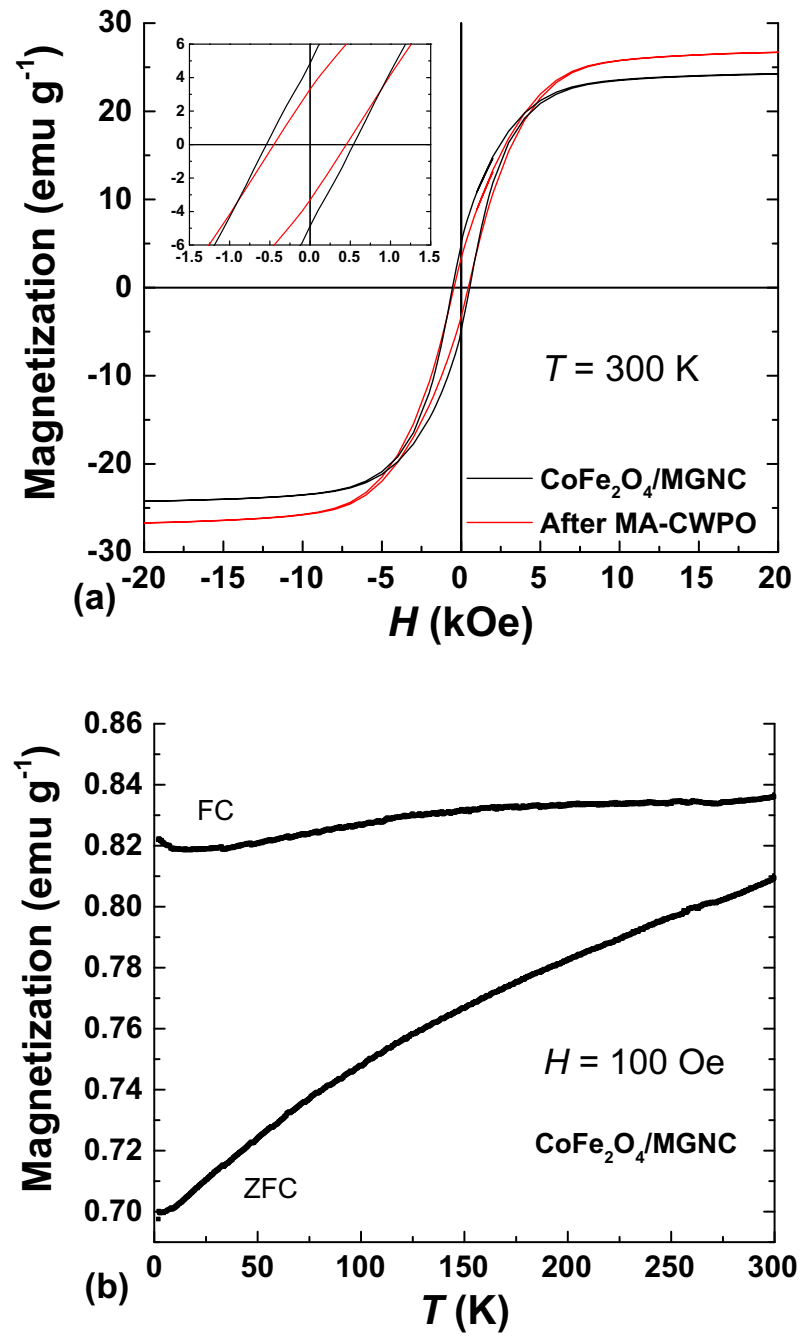

Fig. 3. (a) Field- and (b) temperature-dependent magnetization curves of $\mathrm{CoFe}_{2} \mathrm{O}_{4} / \mathrm{MGNC}$. The hysteresis curves given in (a) were obtained at $T=300 \mathrm{~K}$, with $\mathrm{CoFe}_{2} \mathrm{O}_{4} / \mathrm{MGNC}$ before (as prepared) and after the MA-CWPO reaction stage; the zero-field-cooling (ZFC) and field-cooling (FC) magnetization curves given in (b) were obtained at $H=100$ Oe. The inset of (a) is a zoom of the lowfield region.

\section{Results and discussion}

\subsection{Catalyst characterization}

The $\mathrm{CoFe}_{2} \mathrm{O}_{4} / \mathrm{MGNC}$ material was thoroughly characterized

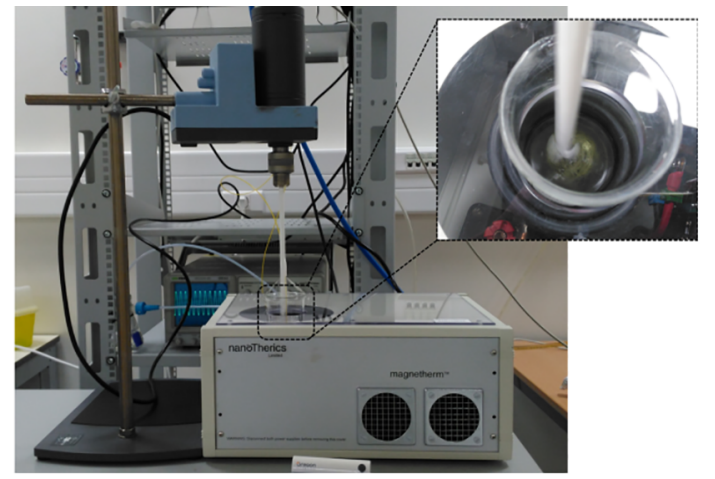

(a)

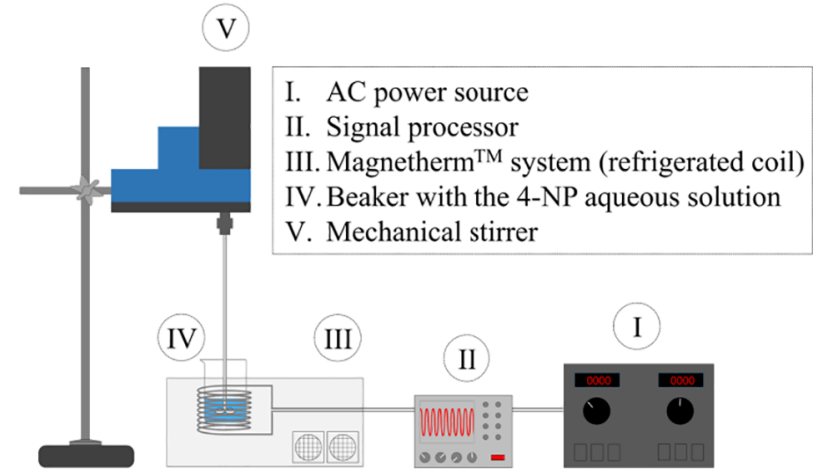

(b)

Fig. 2. Experimental set-up used for the MA-CWPO experiments: (a) front view and (b) schematic representation. Inset of (a): top view of the coil region. 
previously [11]. Nevertheless, the most relevant features are herein briefly referred. $\mathrm{CoFe}_{2} \mathrm{O}_{4} / \mathrm{MGNC}$ is a core-shell hybrid material obtained by encapsulation of $\mathrm{CoFe}_{2} \mathrm{O}_{4}$ nanoparticles within a carbon framework (cf. Fig. 1). Cobalt ferrite $(\mathrm{a}=8.363 \AA$ ), iron $(\mathrm{a}=2.858 \AA$ ) and graphite were identified in the X-ray diffraction (XRD) pattern of $\mathrm{CoFe}_{2} \mathrm{O}_{4} / \mathrm{MGNC}$. The average size of the magnetic cores of $\mathrm{CoFe}_{2} \mathrm{O}_{4} /$ MGNC is $56 \pm 18 \mathrm{~nm}$, as determined from transmission electron microscopy (TEM) measurements. $\mathrm{CoFe}_{2} \mathrm{O}_{4}$ accounts for $14.4 \mathrm{wt} \%$ of $\mathrm{CoFe}_{2} \mathrm{O}_{4}$ /MGNC (as determined by thermogravimetric analysis), which is a micro-mesoporous material with an average pore diameter of $3.75 \mathrm{~nm}$ and a specific surface area $\left(S_{\mathrm{BET}}\right)$ of $330 \mathrm{~m}^{2} \mathrm{~g}^{-1}$. Please refer to our previous publication for additional details [11].

Regarding the magnetic properties, the hysteresis loops $(M v s . H)$ of $\mathrm{CoFe}_{2} \mathrm{O}_{4} / \mathrm{MGNC}$ revealed a saturation magnetization $\left(M_{\mathrm{s}}\right)$ of $24.2 \mathrm{emu} \mathrm{g}^{-1}$, coercivity $\left(H_{\mathrm{c}}\right)$ of $0.54 \mathrm{kOe}$, and saturation remanence $\left(M_{\mathrm{r}}\right)$ of $4.9 \mathrm{emug}^{-1}$ (cf. Fig. 3a), which are characteristic of ferromagnetic materials [15]. In addition, the absence of an interception point between the zero-field-cooling (ZFC) and the field-cooling (FC) magnetization curves (cf. Fig. 3b) shows that the blocking temperature $\left(T_{\mathrm{b}}\right)$ of $\mathrm{CoFe}_{2} \mathrm{O}_{4} / \mathrm{MGNC}$ is above $300 \mathrm{~K}$, further indicating that its magnetic core size is above the single-to-multidomain limit $(\sim 6-7 \mathrm{~nm})$ [21] and so confirming its ferromagnetic behaviour.

\subsection{Magnetically activated catalytic wet peroxide oxidation}

$\mathrm{CoFe}_{2} \mathrm{O}_{4}$ /MGNC was employed in batch CWPO and MA-CWPO experiments performed in the absence and presence of an AC magnetic field, respectively. Additional experiments were performed in order to assess the possible contribution of adsorption and non-catalytic conversion on the 4-NP removal by CWPO and MA-CWPO. All the experiments were performed at room temperature (297.2 $\pm 0.4 \mathrm{~K})$, using the experimental set-up depicted in Fig. 2. Except for the CWPO run, in which the electric current was switched OFF, the experiments depicted in Fig. 4 were performed under the influence of the AC magnetic field described in Section 2.4. As observed, the 4-NP removal obtained after $3 \mathrm{~h}$ of CWPO amounts to $27.7 \%$ of its initial content. This result apparently shows that the application of $\mathrm{CoFe}_{2} \mathrm{O}_{4} / \mathrm{MGNC}$ by itself enables the CWPO of 4-NP under the operating conditions employed. However, a detailed analysis reveals that the 4-NP removal obtained by CWPO matches the sum of the 4-NP removals obtained by adsorption and noncatalytic conversion promoted by $\mathrm{H}_{2} \mathrm{O}_{2}$. Specifically, the 4-NP removal obtained in the non-catalytic run (i.e., in the absence of catalyst) was $11.7 \%$, while the 4-NP removal obtained in pure adsorption run was $16.6 \%$ of its initial content. Since both effects should occur simultaneously in the presence of the solid catalyst and they compete with the $\mathrm{H}_{2} \mathrm{O}_{2}$ assisted process in the CWPO, it is expected that the conversion of 4-NP overcomes that of $\mathrm{H}_{2} \mathrm{O}_{2}$ (given that the latter is in stoichiometric amount). In fact, in the presence of the catalyst depending on the regime of mass transfer the three processes can coexist accounting for the observed discrepancy. This cumulative effect of non-catalytic conversion and adsorption explains why 4-NP conversion is higher than $\mathrm{H}_{2} \mathrm{O}_{2}$ conversion in the CWPO run. A similar phenomenon was observed concerning TOC conversion (cf. Fig. 4). Bearing this in mind, it is possible to conclude that the CWPO system is inefficient for the removal of 4-NP under the operating conditions considered. Nevertheless, a 2.2fold increase, both in 4-NP and TOC conversions, is obtained when CWPO is performed in the presence of the AC magnetic field, through the process here named as magnetically activated catalytic wet peroxide oxidation (MA-CWPO). Likewise, a 2.4-fold increase in $\mathrm{H}_{2} \mathrm{O}_{2}$ consumption is observed (cf. Fig. 4). It should be noted that both 4-NP and TOC conversions are higher than $\mathrm{H}_{2} \mathrm{O}_{2}$ conversion in the MA-CWPO run. This phenomenon can be explained by the cumulative effect of adsorption and catalytic conversion.

The results obtained up to this point suggest that the performance of CWPO in the presence of the ferromagnetic $\mathrm{CoFe}_{2} \mathrm{O}_{4} / \mathrm{MGNC}$ catalyst is enhanced upon application of an AC magnetic field. Additional experiments were performed in order to provide further insights on the reaction mechanisms involved in the MA-CWPO process. Since CWPO relies on the formation of $\mathrm{HO}^{-}$radicals through the reaction described by Eq. (1), the participation of this species in the MA-CWPO process was evaluated. For that purpose, tert-butanol $(t-\mathrm{BuOH})-\mathrm{a}$ strong $\mathrm{HO}^{*}$ radical scavenger $[20,22]$, was added before a MA-CWPO run performed in the presence of $\mathrm{CoFe}_{2} \mathrm{O}_{4} / \mathrm{MGNC}$. As observed in Fig. 4, the 4$\mathrm{NP}$ removal is suppressed by $t$-BuOH. Specifically, the 4-NP removal decreases to $28.3 \%$ of its initial content, which, as previously discussed for the CWPO run, may be ascribed to adsorption and non-catalytic removal promoted by $\mathrm{H}_{2} \mathrm{O}_{2}$. Therefore, this indirect result suggests that $\mathrm{HO}^{\circ}$ radicals are effectively formed during MA-CWPO performed in the presence of $\mathrm{CoFe}_{2} \mathrm{O}_{4} / \mathrm{MGNC}$. It should be noted that TOC was not measured in the experiment performed with $t$-BuOH (cf. Fig. 4). This radical scavenger contributes itself to increasing the TOC content, which would affect the significance of the results obtained in this way.

Additional details on $\mathrm{H}_{2} \mathrm{O}_{2}$, 4-NP and TOC conversions as a function of time in the MA-CWPO run are given in Fig. 5a. As observed, if the MA-CWPO reaction is allowed to proceed during $4 \mathrm{~h}$, the 4-NP conversion reaches $81.3 \%$, representing an average pollutant mass removal rate of $203.4 \mathrm{mg} \mathrm{g}^{-1} \mathrm{~h}^{-1}$. Direct $\mathrm{CO}_{2}$ formation was not followed in this study. Organic carbon mineralization from 4-NP (most likely to $\mathrm{CO}_{2}$ ) was followed by TOC measurements. It was found that the mineralization levels are also very high (as reflected by a TOC abatement of $79 \%$ after $4 \mathrm{~h}$ of reaction, instead of $39 \%$ in the absence of the AC magnetic field), revealing the high efficiency of the MA-CWPO process operated at room temperature. The metal leaching from the $\mathrm{CoFe}_{2} \mathrm{O}_{4} /$ MGNC catalyst was determined at the end of the MA-CWPO run depicted in Fig. 5a. The iron leaching in the treated water amounts to $1.1 \mathrm{mg} \mathrm{L}^{-1}$, a low value when compared to the limit of $2.0 \mathrm{mg} \mathrm{L}^{-1}$ allowed in Portugal and other EU countries for the discharge of treated waters into natural water bodies. The cobalt leaching amounts to $2.1 \mathrm{mg} \mathrm{L}^{-1}$, confirming the higher susceptibility of this metal to undergo leaching to the treated waters [23]. Nevertheless, in this case, there is a lack of discharge limits for treated wastewater and even for drinking water [24].

Concerning the assessment of a possible contribution of metal leaching on 4-NP conversion, we performed a homogeneous CWPO run. For that purpose, a solution containing $\mathrm{Fe}^{2+}$ and $\mathrm{Co}^{2+}$, with the same concentration as that determined at the end of the MA-CWPO run (i.e., 1.1 and $2.1 \mathrm{mg} \mathrm{L}^{-1}$, respectively), was employed as catalyst in the absence of the magnetic field. This approach represents a hypothetical scenario, in which all the metals are leached immediately at the

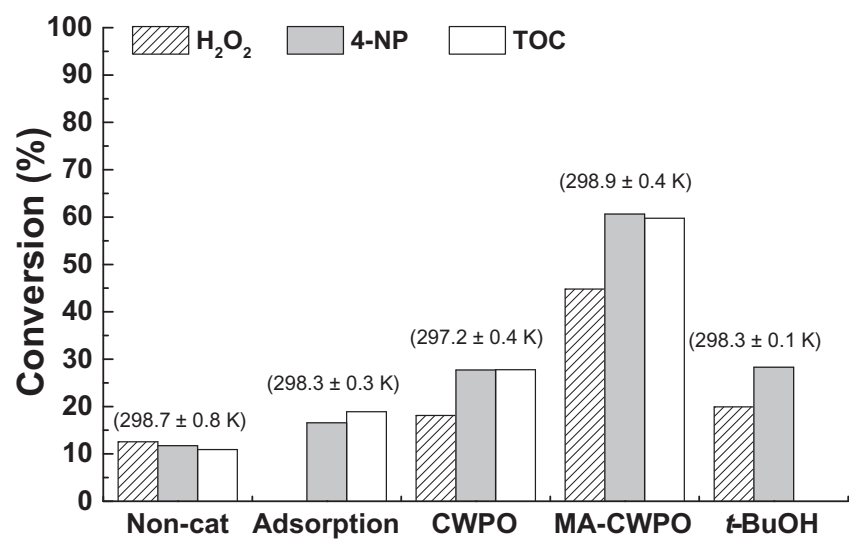

Fig. 4. $\mathrm{H}_{2} \mathrm{O}_{2}$, 4-NP and TOC conversions obtained after $3 \mathrm{~h}$ in non-catalytic (noncat), adsorption, CWPO and MA-CWPO experiments. The effect of tert-butanol ( $t$ $\mathrm{BuOH}$ ) on the $\mathrm{H}_{2} \mathrm{O}_{2}$ and 4-NP conversions by MA-CWPO is also shown. The room temperature during the experiments was $297.2 \pm 0.4 \mathrm{~K}$. The numbers in brackets refer to the solution temperature in each run. Experiments performed with [4$\mathrm{NP}]_{0}=5.0 \mathrm{~g} \mathrm{~L}^{-1}$ and $\mathrm{pH}=3$, and, when applicable, with $\left[\mathrm{CoFe}_{2} \mathrm{O}_{4} /\right.$ $\mathrm{MGNC}]=5.0 \mathrm{gL}^{-1},\left[\mathrm{H}_{2} \mathrm{O}_{2}\right]_{0}=17.8 \mathrm{gL}^{-1}$ and $[t-\mathrm{BuOH}]=60 \mathrm{gL}^{-1}$. 

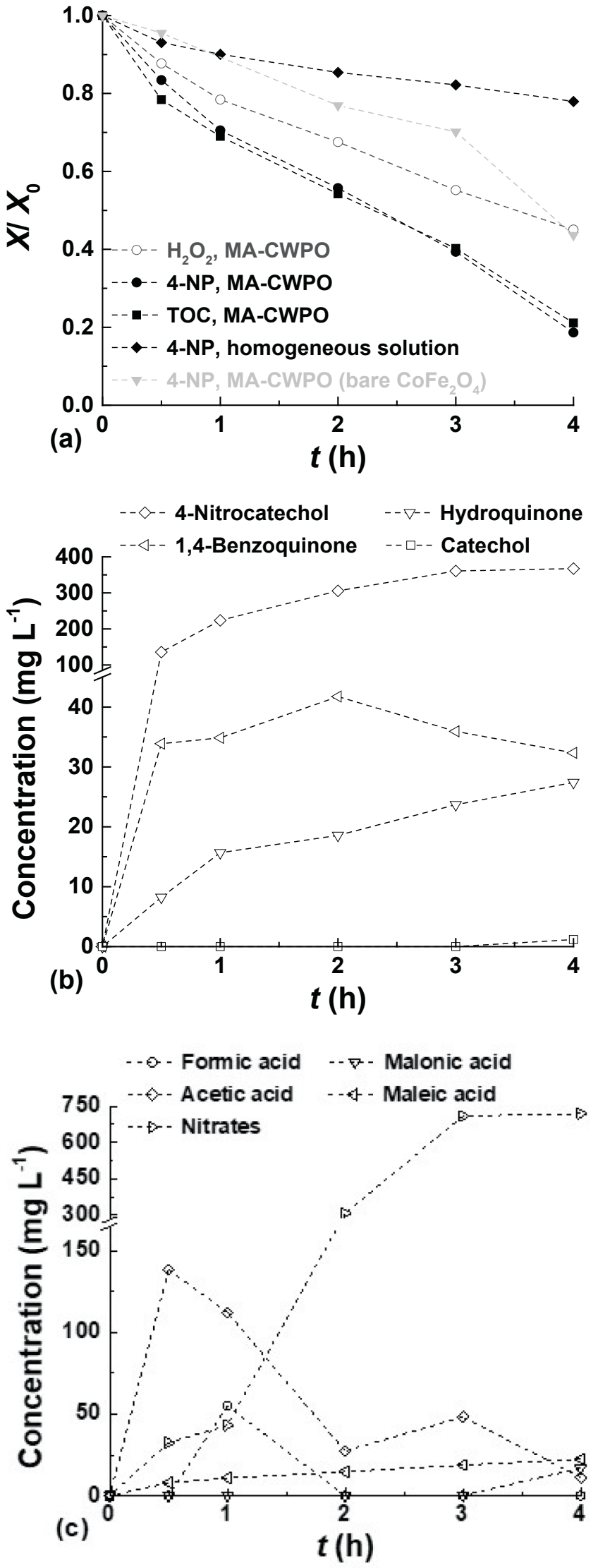

Fig. 5. (a) $\mathrm{H}_{2} \mathrm{O}_{2}$, 4-NP and TOC conversions as a function of time, and evolution of (b) aromatic and (c) non-aromatic by-products of 4-NP oxidation in the MACWPO run performed with $\mathrm{CoFe}_{2} \mathrm{O}_{4} / \mathrm{MGNC}$ under the operating conditions given in Fig. 4. 4-NP removals obtained in the run performed with the homogeneous solution $\left(\left[\mathrm{Fe}^{2+}\right]=1.1 \mathrm{mg} \mathrm{L}^{-1}\right.$ and $\left[\mathrm{Co}^{2+}\right]=2.1 \mathrm{mg} \mathrm{L}^{-1}$, corresponding to the amounts leached during the MA-CWPO run), and in the MACWPO run performed with bare $\mathrm{CoFe}_{2} \mathrm{O}_{4}\left(\left[\mathrm{CoFe}_{2} \mathrm{O}_{4}\right]=0.72 \mathrm{~g} \mathrm{~L}^{-1}\right.$, corresponding to $14.4 \mathrm{wt} \%$ of $\mathrm{CoFe}_{2} \mathrm{O}_{4} / \mathrm{MGNC}$ ), are also given in (a) for comparison.

beginning of the MA-CWPO run. Nevertheless, even under these conditions the results show that the 4-NP removal obtained is negligible (cf. Fig. 5a), since it is only ca. $6 \%$ higher than that obtained in the noncatalytic run (i.e., in the absence of catalyst; cf. Fig. 4). These observations highlight the heterogeneous nature of the MA-CWPO process performed in the presence of $\mathrm{CoFe}_{2} \mathrm{O}_{4} / \mathrm{MGNC}$.

In order to infer about possible effects of MA-CWPO on the properties of $\mathrm{CoFe}_{2} \mathrm{O}_{4} / \mathrm{MGNC}$, the catalyst was recovered after the MACWPO reaction stage, its magnetic properties being determined by SQUID-VSM. As observed in Fig. 3a, the magnetic properties of $\mathrm{CoFe}_{2} \mathrm{O}_{4} /$ MGNC are apparently slightly affected, the saturation magnetization $\left(M_{\mathrm{S}}\right)$ increasing from $24.2 \mathrm{emu} \mathrm{g}^{-1}$, in the as-prepared $\mathrm{CoFe}_{2} \mathrm{O}_{4} / \mathrm{MGNC}$, to $26.7 \mathrm{emu} \mathrm{g}^{-1}$, in the used catalyst (corresponding to a $10 \%$ increase). A similar behaviour was observed regarding both coercivity $\left(H_{\mathrm{c}}\right)$ and remanent magnetization $\left(M_{\mathrm{r}}\right)$. However, it should be noted that $\mathrm{CoFe}_{2} \mathrm{O}_{4}$ accounts for only $14.4 \mathrm{wt} \%$ of $\mathrm{CoFe}_{2} \mathrm{O}_{4} / \mathrm{MGNC}$, the remaining phase being mostly graphitic carbon. This composition makes it very difficult to compare the catalyst before and after reaction. For instance, a standard deviation of $5 \%$ was obtained upon duplicate determination of the saturation magnetization $\left(M_{\mathrm{S}}\right)$ of the as-prepared $\mathrm{CoFe}_{2} \mathrm{O}_{4} / \mathrm{MGNC}$ catalyst. Taking all this into account, it is suggested that the magnetic properties of $\mathrm{CoFe}_{2} \mathrm{O}_{4} / \mathrm{MGNC}$ are not significantly affected during its application in MA-CWPO.

The benefits of carbon encapsulation were clearly established in our previous publication devoted to the synthesis and application of a hybrid magnetic graphitic nanocomposite in CWPO [25]. In that study, the composite catalyst was prepared through the same synthesis procedure herein considered, except that magnetite was encapsulated within a graphitic shell instead of $\mathrm{CoFe}_{2} \mathrm{O}_{4}$ [25]. Nevertheless, in order to shed some light on the role of the carbon shell when $\mathrm{CoFe}_{2} \mathrm{O}_{4} / \mathrm{MGNC}$ is employed in MA-CWPO, an additional experiment was performed in the presence of bare $\mathrm{CoFe}_{2} \mathrm{O}_{4}$. It was found that the 4-NP removal obtained in the presence of $\mathrm{CoFe}_{2} \mathrm{O}_{4}$ is lower than that obtained with $\mathrm{CoFe}_{2} \mathrm{O}_{4} / \mathrm{MGNC}$ (cf. Fig. 5a), allowing to confirm that the performance of bare $\mathrm{CoFe}_{2} \mathrm{O}_{4}$ in MA-CWPO is enhanced when this magnetic material is encapsulated within a graphitic structure to yield $\mathrm{CoFe}_{2} \mathrm{O}_{4} /$ MGNC. This superior performance can be ascribed to the presence of the carbon phase, which increases the adsorptive interactions between the pollutant molecules and the surface of the catalyst, thus leading to further oxidation [25]. Please refer to our previous publication for additional details [25].

The 4-NP oxidation/mineralization mechanism by MA-CWPO was also studied. It was found that both the aromatic and non-aromatic byproducts detected during the MA-CWPO experiment (cf. Fig. 5b and c, respectively) are consistent with the reaction mechanism proposed in our previous studies devoted to CWPO [11,18,25]. Briefly, the 4-NP molecule is attacked by the $\mathrm{HO}^{\circ}$ radicals up to a point in which the aromatic ring is opened, and several low molecular weight carboxylic acids are formed. As observed in Fig. 5b, most of the aromatic intermediates of 4-NP oxidation are present in low amounts; even 4-nitrocatechol, the main aromatic intermediate of 4-NP CWPO, never surpasses a concentration around $350 \mathrm{mg} \mathrm{L}^{-1}$. This is a very low value compared to those obtained in our previous studies devoted to the CWPO of 4-NP (in the range $1400-1600 \mathrm{mg} \mathrm{L}^{-1}$, for similar 4-NP conversions) $[11,23,25]$, including that performed with the $\mathrm{CoFe}_{2} \mathrm{O}_{4}$ / MGNC catalyst [11]. In addition, the concentration curves in Fig. 5c 

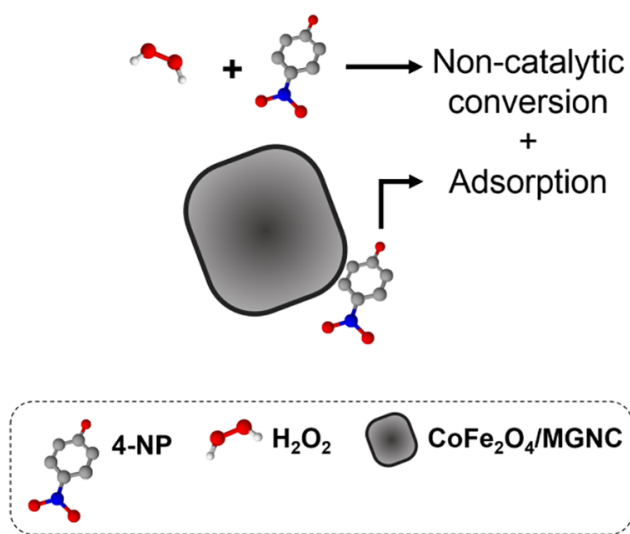

(a)

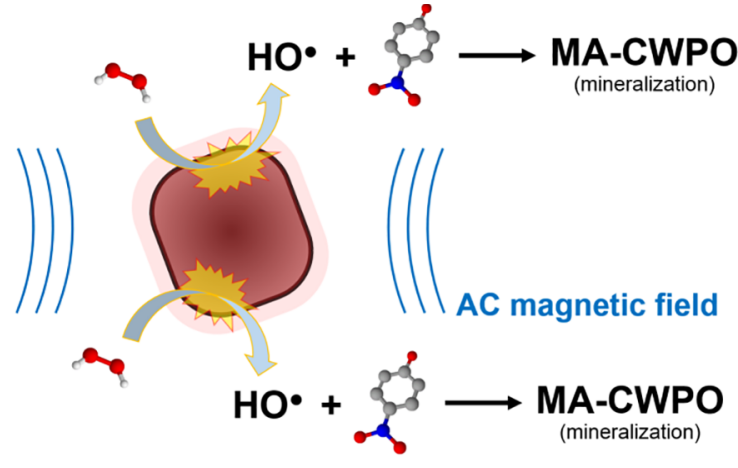

(b)

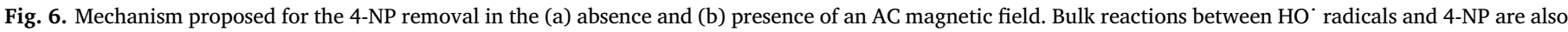
represented in (a).

show that most of the carboxylic acids formed by aromatic ring opening are consequently converted afterwards. These observations highlight the high mineralization efficiency obtained by MA-CWPO in the presence of $\mathrm{CoFe}_{2} \mathrm{O}_{4} / \mathrm{MGNC}$. At the same time, nitrates can be produced by oxidation of the $-\mathrm{NO}_{2}$ group from the 4-NP molecule. $\mathrm{The}^{\mathrm{NO}_{3}}{ }^{-}$concentration curve given in Fig. $5 \mathrm{c}$ allows to conclude that at least $32.3 \%$ of the total nitrogen initially present in the 4-NP $5 \mathrm{~g} \mathrm{~L}^{-1}$ solution was effectively subtracted from the main aromatic ring after $4 \mathrm{~h}$ of MACWPO. Additional details on the reaction mechanism where previously established [18].

As discussed in Section 3.1, $\mathrm{CoFe}_{2} \mathrm{O}_{4}$ /MGNC is a ferromagnetic material. It is known that these materials are able to convert magnetic energy into thermal energy, when exposed to an AC magnetic field [14-16]. In ferromagnetic materials, this phenomenon occurs mainly due to hysteresis losses, i.e., the thermal energy released in each magnetization cycle depicted in Fig. 3a [16]. The solution temperature during the MA-CWPO run performed in the presence of $\mathrm{CoFe}_{2} \mathrm{O}_{4}$ /MGNC was not significantly higher than that recorded during the non-catalytic experiment performed in the absence of catalyst (cf. Fig. 4). These results can be explained in terms of the low $\mathrm{CoFe}_{2} \mathrm{O}_{4}$ concentration employed ( $0.72 \mathrm{~g} \mathrm{~L}^{-1}$, corresponding to $14.4 \mathrm{wt} \%$ of $\left.\mathrm{CoFe}_{2} \mathrm{O}_{4} / \mathrm{MGNC}\right)$ and by $\mathrm{CoFe}_{2} \mathrm{O}_{4} / \mathrm{MGNC}$ nanoparticle agglomeration, which are crucial parameters affecting heat release [14]. These parameters were not optimized in this study. Nevertheless, the localised increase of $\mathrm{CoFe}_{2} \mathrm{O}_{4} / \mathrm{MGNC}$ surface temperature upon exposure to an AC magnetic field accounts for the superior performance of MA-CWPO for the removal of 4-NP at room temperature, when compared to that obtained by CWPO. As recently proposed for microwave-assisted catalytic wet peroxide oxidation (MW-CWPO) [26,27], the localised increase of $\mathrm{CoFe}_{2} \mathrm{O}_{4}$ /MGNC surface temperature, which accelerates the catalytic decomposition of $\mathrm{H}_{2} \mathrm{O}_{2}$ via $\mathrm{HO}^{-}$radicals formation, can be held responsible for the superior performance of MA-CWPO. Fig. 6 depicts the alternative routes proposed for the 4-NP removal by CWPO and MACWPO.

Temperature is typically regarded as a very important operating parameter in CWPO (and in the Fenton process, a particular case of CWPO), as reflected by the recent trend for the application of higher operating temperatures (up to $398.2 \mathrm{~K}$ ) [28-30]. Therefore, the possibility investigated in the present study to promote the decomposition of $\mathrm{H}_{2} \mathrm{O}_{2}$ via $\mathrm{HO}^{-}$radicals formation at room temperature offers an alternative route for the development of more efficient water and wastewater treatment processes.

\section{Conclusions}

Here is described for the first time the tandem effect of a magnetic field on catalytic wet peroxide oxidation application, in a process here coined as magnetically activated catalytic wet peroxide oxidation (MACWPO).

The MA-CWPO process markedly increase both 4-NP removal and organic mineralization with respect to the non-magnetic equivalent process. This superior performance was explained by the localized increase of the surface temperature of the $\mathrm{CoFe}_{2} \mathrm{O}_{4} / \mathrm{MGNC}$ ferromagnetic catalyst, upon conversion of magnetic energy into thermal energy. The higher surface temperature promotes the formation of highly active sites for the catalytic decomposition of $\mathrm{H}_{2} \mathrm{O}_{2}$ via $\mathrm{HO}^{\circ}$ radicals formation, thus increasing the subsequent 4-NP conversion.

The results reported in this study open future prospects for the development of more efficient water and wastewater treatment processes performed at room temperature and atmospheric pressure.

\section{Acknowledgments}

This work was financially supported by: Project POCI-01-0145FEDER-006984 - Associate Laboratory LSRE-LCM funded by FEDER through COMPETE2020 - Programa Operacional Competitividade e Internacionalização (POCI) - and by national funds through FCTFundação para a Ciência e a Tecnologia; Project VALORCOMP, funded by FEDER through Programme INTERREG V-A Spain - Portugal (POCTEP) 2014-2020. R.S. Ribeiro acknowledges the FCT individual Ph.D. grant SFRH/BD/94177/2013, with financing from FCT and the European Social Fund (through POPH and QREN). M.B-L. also thanks NORTE 2020 (2014-2020 North Portugal Regional Operational Programme) and the ERDF (European Regional Development Fund) under the Grant NORTE-01-0145-FEDER-000019.

\section{References}

[1] M. Munoz, Z.M. de Pedro, J.A. Casas, J.J. Rodríguez, Preparation of magnetitebased catalysts and their application in heterogeneous Fenton oxidation - A review, Appl. Catal. B 176-177 (2015) 249-265.

[2] R.S. Ribeiro, A.M.T. Silva, J.L. Figueiredo, J.L. Faria, H.T. Gomes, Catalytic wet peroxide oxidation: a route towards the application of hybrid magnetic carbon nanocomposites for the degradation of organic pollutants. A review, Appl. Catal. B 187 (2016) 428-460.

[3] P.V. Nidheesh, Heterogeneous Fenton catalysts for the abatement of organic pollutants from aqueous solution: a review, RSC Adv. 5 (2015) 40552-40577.

[4] M. Muruganandham, R.P.S. Suri, M. Sillanpää, J.J. Wu, B. Ahmmad, S. Balachandran, M. Swaminathan, Recent developments in heterogeneous catalyzed environmental remediation processes, J. Nanosci. Nanotechnol. 14 (2014) 1898-1910.

[5] S. Rahim Pouran, A.A. Abdul Raman, W.M.A. Wan Daud, Review on the application of modified iron oxides as heterogeneous catalysts in Fenton reactions, J. Cleaner Prod. 64 (2014) 24-35.

[6] M.C. Pereira, L.C.A. Oliveira, E. Murad, Iron oxide catalysts: Fenton and Fenton-like reactions - A review, Clay Miner. 47 (2012) 285-302. 
[7] A. Dhakshinamoorthy, S. Navalon, M. Alvaro, H. Garcia, Metal nanoparticles as heterogeneous Fenton catalysts, ChemSusChem 5 (2012) 46-64.

[8] S. Navalon, A. Dhakshinamoorthy, M. Alvaro, H. Garcia, Heterogeneous Fenton catalysts based on activated carbon and related materials, ChemSusChem 4 (2011) 1712-1730.

[9] S. Navalon, M. Alvaro, H. Garcia, Heterogeneous Fenton catalysts based on clays, silicas and zeolites, Appl. Catal. B 99 (2010) 1-26.

[10] P.R. Gogate, A.B. Pandit, A review of imperative technologies for wastewater treatment I: oxidation technologies at ambient conditions, Adv. Environ. Res. 8 (2004) 501-551.

[11] R.S. Ribeiro, R.O. Rodrigues, A.M.T. Silva, P.B. Tavares, A.M.C. Carvalho, J.L. Figueiredo, J.L. Faria, H.T. Gomes, Hybrid magnetic graphitic nanocomposites towards catalytic wet peroxide oxidation of the liquid effluent from a mechanical biological treatment plant for municipal solid waste, Appl. Catal. B 219 (2017) 645-657.

[12] Y.V. Kolen’ko, M. Bañobre-López, C. Rodríguez-Abreu, E. Carbó-Argibay, A. Sailsman, Y. Piñeiro-Redondo, M.F. Cerqueira, D.Y. Petrovykh, K. Kovnir, O.I. Lebedev, J. Rivas, Large-scale synthesis of colloidal $\mathrm{Fe}_{3} \mathrm{O}_{4}$ nanoparticles exhibiting high heating efficiency in magnetic hyperthermia, J. Phys. Chem. C 118 (2014) 8691-8701.

[13] M. Bañobre-López, A. Teijeiro, J. Rivas, Magnetic nanoparticle-based hyperthermia for cancer treatment, Rep. Pract. Oncol. Radiother. 18 (2013) 397-400.

[14] A.E. Deatsch, B.A. Evans, Heating efficiency in magnetic nanoparticle hyperthermia, J. Magn. Magn. Mater. 354 (2014) 163-172.

[15] I. Sharifi, H. Shokrollahi, S. Amiri, Ferrite-based magnetic nanofluids used in hyperthermia applications, J. Magn. Magn. Mater. 324 (2012) 903-915.

[16] A. Hervault, N.T.K. Thanh, Magnetic nanoparticle-based therapeutic agents for thermo-chemotherapy treatment of cancer, Nanoscale 6 (2014) 11553-11573.

[17] V.F. Cardoso, A. Francesko, C. Ribeiro, M. Bañobre-López, P. Martins, S. LancerosMendez, Advances in magnetic nanoparticles for biomedical applications, Adv. Healthcare Mater. 7 (2018) 1700845.

[18] R.S. Ribeiro, A.M.T. Silva, L.M. Pastrana-Martínez, J.L. Figueiredo, J.L. Faria, H.T. Gomes, Graphene-based materials for the catalytic wet peroxide oxidation of highly concentrated 4-nitrophenol solutions, Catal. Today 249 (2015) 204-212.

[19] R.O. Rodrigues, M. Bañobre-López, J. Gallo, P.B. Tavares, A.M.T. Silva, R. Lima,
H.T. Gomes, Haemocompatibility of iron oxide nanoparticles synthesized for theranostic applications: a high-sensitivity microfluidic tool, J. Nanopart. Res. 18 (2016) 194.

[20] A. Aguinaco, J.P. Pocostales, J.F. García-Araya, F.J. Beltrán, Decomposition of hydrogen peroxide in the presence of activated carbons with different characteristics, J. Chem. Technol. Biotechnol. 86 (2011) 595-600.

[21] S. Gyergyek, M. Drofenik, D. Makovec, Oleic-acid-coated $\mathrm{CoFe}_{2} \mathrm{O}_{4}$ nanoparticles synthesized by co-precipitation and hydrothermal synthesis, Mater. Chem. Phys. 133 (2012) 515-522.

[22] W.H. Glaze, J.-W. Kang, D.H. Chapin, The chemistry of water treatment processes involving ozone, hydrogen peroxide and ultraviolet radiation, Ozone Sci. Eng. 9 (1987) 335-352.

[23] R.S. Ribeiro, A.M.T. Silva, J.L. Figueiredo, J.L. Faria, H.T. Gomes, The role of cobalt in bimetallic iron-cobalt magnetic carbon xerogels developed for catalytic wet peroxide oxidation, Catal. Today 296 (2017) 66-75.

[24] E.P. Agency, Parameters of Water Quality: Interpretation and Standards, Environmental Protection Agency, Ireland, Wexford, Ireland, 2001.

[25] R.S. Ribeiro, A.M.T. Silva, P.B. Tavares, J.L. Figueiredo, J.L. Faria, H.T. Gomes, Hybrid magnetic graphitic nanocomposites for catalytic wet peroxide oxidation applications, Catal. Today 280 (2017) 184-191.

[26] A.L. Garcia-Costa, J.A. Zazo, J.J. Rodríguez, J.A. Casas, Microwave-assisted catalytic wet peroxide oxidation. Comparison of Fe catalysts supported on activated carbon and $\gamma$-alumina, Appl. Catal. B 218 (2017) 637-642.

[27] B. Zhang, H. You, F. Wang, Microwave-enhanced catalytic wet peroxide oxidation of quinoline: the influence of $\mathrm{pH}$ and $\mathrm{H}_{2} \mathrm{O}_{2}$ dosage and identification of reactive oxygen species, RSC Adv. 7 (2017) 14769-14775.

[28] C.M. Domínguez, A. Quintanilla, J.A. Casas, J.J. Rodríguez, Treatment of real winery wastewater by wet oxidation at mild temperature, Sep. Purif. Technol. 129 (2014) 121-128.

[29] Y. Yan, S. Jiang, H. Zhang, Efficient catalytic wet peroxide oxidation of phenol over Fe-ZSM-5 catalyst in a fixed bed reactor, Sep. Purif. Technol. 133 (2014) 365-374.

[30] G. Pliego, J.A. Zazo, P. Garcia-Muñoz, M. Munoz, J.A. Casas, J.J. Rodríguez, Trends in the intensification of the Fenton process for wastewater treatment: an overview, Crit. Rev. Env. Sci. Technol. 45 (2015) 2611-2692. 